\title{
Iodine isotope ratios and halide concentrations in fluids of the Satsuma-Iwojima volcano, Japan
}

\author{
G. T. Snyder ${ }^{1}$, U. Fehn ${ }^{1}$, and F. Goff ${ }^{2}$ \\ ${ }^{1}$ Department of Earth and Environmental Sciences, University of Rochester, Rochester, NY 14627, U.S.A. \\ ${ }^{2}$ Los Alamos National Laboratory, Los Alamos, NM 87545, U.S.A.
}

(Received April 13, 2000; Revised May 7, 2001; Accepted May 14, 2001)

\begin{abstract}
Fumarolic condensates and acid spring waters from Satsuma-Iwojima were sampled between 1993 and 1998 and analyzed for ${ }^{129} \mathrm{I} / \mathrm{I}$ and ${ }^{36} \mathrm{Cl} / \mathrm{Cl}$ ratios and chloride, bromine, and iodine concentrations. Halogen concentrations suggest that the fumarolic condensates represent mostly magmatic fluids, but that the hot springs are a mixture between magmatic fluids and meteoric water with some presence of seawater. The magmatic component is best preserved in the high-temperature fumaroles collected in 1998 and has a ${ }^{129} \mathrm{I} / \mathrm{I}$ ratio of $756 \pm 47 \times 10^{-15}$. This ${ }^{129} \mathrm{I} / \mathrm{I}$ ratio yields an iodine age of $15.5 \pm 1.5 \mathrm{Ma}$, which is compatible with derivation of iodine from subducted marine sediments in this region. Ratios of $\mathrm{I} / \mathrm{Cl}$, and $\mathrm{Br} / \mathrm{Cl}$ in the fumaroles also indicate that halides in the magmatic component were mainly derived from marine sediments subducted in the Nankai Trough. These observations suggest that recycling of subducted sediments is an active source of halides in the Satsuma-Iwojima volcanic system. The comparison of ${ }^{129} \mathrm{I} / \mathrm{I}$ ratios obtained from fumaroles over the sampling period shows that a recent meteoric component was present in 1993, but not in 1998. This observation might reflect reorganization of the fumarolic system during this period, which expelled the more recent meteoric water from the fumarolic system after 1993. The acid hot springs on the flanks of the volcano maintain a ${ }^{129} \mathrm{I}$ isotopic signature indicative of substantial dilution of magmatic waters by mixing with old meteoric water and seawater. Fumarolic gases and hot spring waters were also analyzed for ${ }^{36} \mathrm{Cl} / \mathrm{Cl}$, but the measured ratios were at, or below, the detection limit of AMS, also indicating that recent contributions of $\mathrm{Cl}$ from meteoric water are small in the fumaroles and coastal hot springs.
\end{abstract}

\section{Introduction}

Volcanic centers provide an ongoing flux of elements to the earth's surface. The more volatile components, which at times are the cause of violent eruptions, may be derived from primordial mantle sources or from magmatic interactions with fluids in the overlying crust. Also of major importance is the role of subducted oceanic crust and sediments, which provide hydrous fluids that flux the overlying mantle wedge and provide constituents to the evolving island arc magmas. An understanding of the source of magmatic volatiles in island arc settings is important for the determination of the impact that subduction has on global geochemical cycles.

The main purpose of this study was to investigate applications of the cosmogenic isotope systems of ${ }^{129} \mathrm{I}$ and ${ }^{36} \mathrm{Cl}$ for tracing studies in subduction zones. Two natural sources exist for ${ }^{129} \mathrm{I}$ (half-life $15.7 \mathrm{Ma}$ ), the spallation of Xe isotopes in the atmosphere and spontaneous fission in the crust, both of which contribute at similar rates to the ${ }^{129} \mathrm{I}$ budget of the oceans (Fabryka-Martin et al., 1985). The ${ }^{129} \mathrm{I} / \mathrm{I}$ ratio, in ocean water and in recent sediments, was $1500 \times 10^{-15}$, before the addition of anthropogenic ${ }^{129}$ I raised the level in all surface compartments by several orders of magnitude (Moran et al., 1998). This input ratio is used for the initial

Copy right(C) The Society of Geomagnetism and Earth, Planetary and Space Sciences (SGEPSS); The Seismological Society of Japan; The Volcanological Society of Japan; The Geodetic Society of Japan; The Japanese Society for Planetary Sciences. age calculations based on the ${ }^{129} \mathrm{I}$ system. The ${ }^{36} \mathrm{Cl}$ system has less potential in this context, because of its relatively short half-life $(301,000$ a) and the fact that oceanic ratios are below the detection limit $\left(1 \times 10^{-15}\right)$ of accelerator mass spectrometry (AMS) systems. It is here used only for the detection of the potential presence of surface waters carrying an anthropogenic signal.

The two isotopic systems have been used previously either separately or in combination as natural tracers in studies involving the migration of hydrothermal fluids (Hedenquist et al., 1990; Fehn et al., 1992; Rao et al., 1996), oil and gas field brines (Moran et al., 1995; Snyder et al., 2000), and methane hydrate pore fluids (Fehn et al., 2000). Iodine is incompatible with most minerals found in igneous rocks and also partitions readily into fluids from melts (Bureau et $a l ., 2000)$. The long half-life of ${ }^{129}$ I permits the determination of iodine ages up to $80 \mathrm{Ma}$, which covers the age-range necessary to determine the age of present marine sediments as well as subducted iodine signatures (Snyder and Fehn, 2000). Determinations of bromide and chloride concentrations help to assess the origin and the relative mobility of the halides in high-temperature systems.

In this study we analyzed samples from high-temperature fumaroles and hot springs collected at Satsuma-Iwojima between 1993 and 1998 in order to determine the contribution of iodine from both magmatic and meteoric sources. The Satsuma-Iwojima volcano of Japan has been selected for 
this study because of the accessibility of high-temperature fumaroles and the availability of an extensive geochemical data set compiled in recent decades (Matsuo et al., 1974; Kanzaki et al., 1979; Shinohara et al., 1993; Hedenquist et al., 1994; Goff and McMurtry, 2000). Another important consideration in selecting Satsuma-Iwojima is the availability of data from ODP Site 808 in the Nankai Trough, roughly $500 \mathrm{~km}$ to the northeast. This drill site provides important data concerning the age of subducted sediments in this area (Olafsson, 1993) and on the composition of sediment pore fluids of the Philippine Sea Plate in the initial stages of subduction beneath the Eurasian plate (You et al., 1993, Kastner et al., 1993).

\section{Geologic Setting}

The volcanic island of Satsuma-Iwojima lies $50 \mathrm{~km}$ south of Kyushu, Japan, and is part of the submerged Kikai caldera, which was formed 6300 years ago (Shinohara et al., 1993; Hedenquist et al., 1994). The most recent eruption on Satsuma-Iwojima occurred 500 to 600 years ago. Iwodake, the active volcano on the island, is a calc-alkaline rhyolite dome. The summit crater hosts several high temperature fumaroles with temperatures up to $880^{\circ} \mathrm{C}$, which are related to passive degassing of a shallow magma body. During the period from 1994 to 1997, degassing of the volcano became more intense and was accompanied by a major reorganization of the fumaroles from the margins of the Iwodake dome to the crater floor. Shinohara et al. (2002) suggest that this is a result of the change in the convection rate of the underlying magma body, although the mechanism for this change is not well understood. Acid springs discharge on the northern and southern outer flanks of the volcano, generally at elevations less than $5 \mathrm{~m}$ above sea level. Discoloration of seawater along the coastline attests to discharge of acid waters also below sea level (Hedenquist et al., 1994). Based on $\delta \mathrm{D}$ and $\delta^{18} \mathrm{O}$ values, Matsuo et al. (1974) found that the spring waters were, for the most part, mixtures of magmatic and meteoric waters. Shinohara et al. (1993) arrived at the same conclusion and calculated a mixing ratio between meteoric water and magmatic gases in the acid springs ranging from 1:1 to 7:1. Tritium and stable isotope data suggest the presence of surface seawater in some of the hot springs near sea level (Goff and McMurtry, 2000).

Satsuma-Iwojima is related to the subduction of the Philippine Sea Plate under the Eurasian Plate in the Nankai Trough. The age of the oceanic crust at the trough is 15 $\mathrm{Ma}$, while sediment ages under the decollement (ODP 808) where found to be between 5 and $15 \mathrm{Ma}$ old (Olafsson, 1993). With an arc-trench gap of $150 \mathrm{~km}$, an average subduction angle of $40^{\circ}$ and a convergence rate of $3.8 \mathrm{~cm} / \mathrm{yr}$ (Urrutia and Morton, 1997), oceanic crust and sediments have increased in age by $5 \mathrm{Ma}$ by the time they have reached the region under Satsuma-Iwojima.

\section{Methods}

Fumarolic condensates and hot spring waters were collected from Satsuma-Iwojima during 1993, 1997 and 1998. The sampling methods as well as the locations of the fumaroles and hot springs are described in Goff and McMurtry (2000) and Shinohara et al. (2002). Chloride concentra- tions were determined by ion chromatography, iodine, and bromine concentrations were measured using a VG Plasmaquad II ICP-MS following established methods (Takaku et al., 1995; Schnetger and Muramatsu, 1996; Gélinas et al., 1998).

Extraction and sample purification for AMS determination was carried out with four of the fumaroles and one hot spring using methods outlined in Fehn et al. (1992). Samples were filtered and sodium bisulfite was used to reduce any iodate that might have been present in the samples. In the case of both iodine and chlorine, purification and preconcentration was carried out using anion resin (BioRad). Iodine was extracted into chloroform and then back-extracted using sodium bisulfite. Samples were precipitated as AgI and $\mathrm{AgCl}$ and analyzed at the AMS system of PRIME Laboratory, Purdue University (Sharma et al., 2000). Isotopic ratios are presented with $1-\sigma$ precision errors determined at PRIME.

\section{Results}

Concentrations and isotope ratios for the samples are listed in Table 1. Concentrations of iodine in the fumarolic condensates are two orders of magnitude greater than that of seawater, while bromine and chlorine concentrations are slightly less than that of seawater. There is no clear correlation between temperatures and halogen concentrations in the fumaroles, except that the only fumarole not following the trend, Kotake (\#7), is also the only low-temperature fumarole and has much lower concentrations than the other fumaroles, especially for iodine and bromine. The fumaroles have halogen concentrations quite similar to those observed in Miocene pore fluids in the sediments of the Nankai Trough (ODP 808; Kastner et al., 1993; You et al., 1993). There is also good agreement in $\mathrm{I} / \mathrm{Cl}$ and $\mathrm{Br} / \mathrm{Cl}$ ratios in fumaroles, pore fluids and volcanic rocks of Satsuma-Iwojima (Yoshida et al., 1971).

In contrast to the fumarolic condensates, the coastal hot springs all have iodine concentrations that are only slightly greater than in seawater, but have chloride and bromine concentrations lower by one order of magnitude than that of seawater. The two seawater samples collected close to shore have concentrations essentially identical to common seawater values.

Only five of the samples had sufficient amounts of iodine to allow the determination of ${ }^{129} \mathrm{I} / \mathrm{I}$ ratios. The ratios found for these samples were between $4360 \times 10^{-15}$ and $754 \times$ $10^{-15}$. All of these ratios are substantially below present anthropogenic levels (approximately $5 \times 10^{-9}$ in Japan, Fehn and Snyder, 2000) and three of them had ratios below the pre-anthropogenic level of $1500 \times 10^{-15}$. The fumaroles sampled in 1993 had iodine ratios above pre-anthropogenic levels, suggesting a ${ }^{129} \mathrm{I}$ contribution from recent meteoric sources. The ${ }^{36} \mathrm{Cl} / \mathrm{Cl}$ values determined for the fumaroles and the hot spring are all essentially at the detection limit of the AMS system $\left(1 \times 10^{-15}\right)$, a result, which, combined with a relatively large precision error, does not permit a quantitative analysis of these data. 


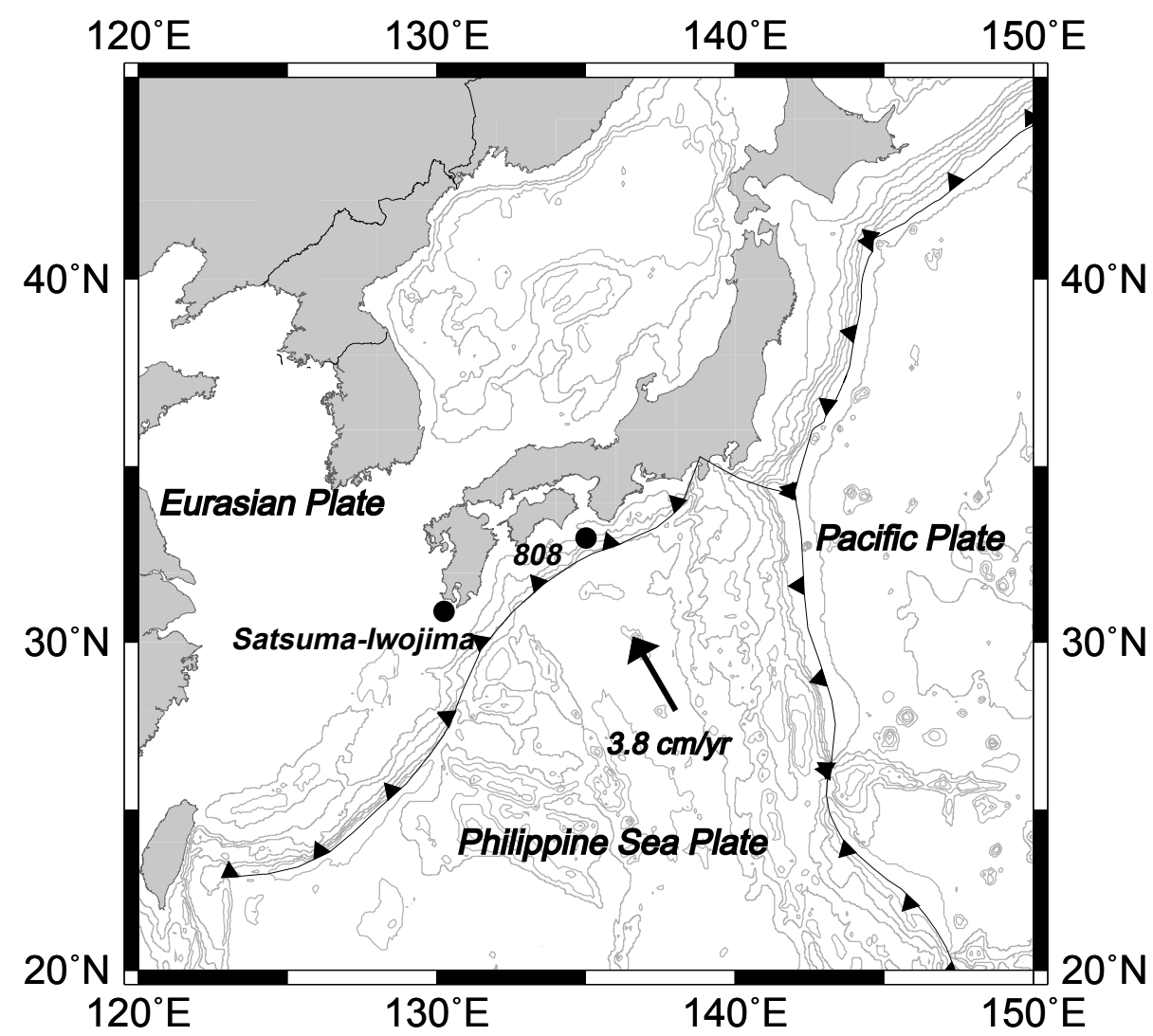

(a)

\section{Satsuma-Iwojima}

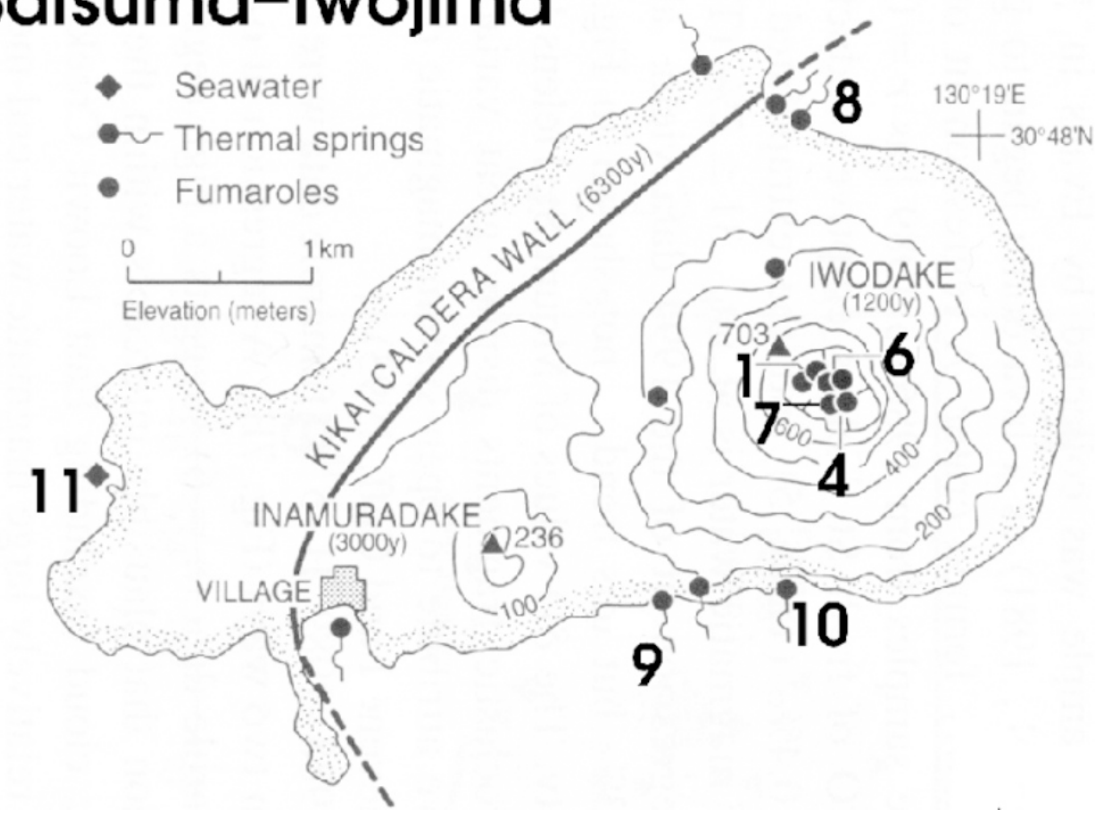

(b)

Fig. 1. Tectonic setting (a) and sampling locations (b). Numbers correspond to sample numbers in Table 1.

\section{Discussion}

5.1 Composition of the magmatic component in volcanic fluids

The main purpose of this study was to test whether the

${ }^{129} \mathrm{I} / \mathrm{I}$ ratios detected in these samples can be related to the origin of volcanic fluids and particularly to remobilization from marine sediments in the Satsuma-Iwojima system. Given the variation in the ${ }^{129} \mathrm{I} / \mathrm{I}$ ratios, the composition of the magmatic component in the samples needs to be reviewed first, which is done here in two stages. First we derive the 
Table 1. Chemical and isotopic data for samples collected at Satsuma-Iwojima.

\begin{tabular}{|c|c|c|c|c|c|c|c|c|c|c|c|}
\hline No & Location & Sample ID & Date & $\begin{array}{c}\mathrm{T} \\
\left({ }^{\circ} \mathrm{C}\right)\end{array}$ & $\begin{array}{c}\mathrm{I} \\
(\mu \mathrm{M})\end{array}$ & $\begin{array}{c}\mathrm{Cl} \\
(\mathrm{mM})\end{array}$ & $\begin{array}{c}\mathrm{Br} \\
(\mu \mathrm{M})\end{array}$ & $\begin{array}{c}{ }^{129} \mathrm{I} / \mathrm{I} \\
\left(10^{-15}\right)\end{array}$ & $\begin{array}{l}{ }^{36} \mathrm{Cl} / \mathrm{Cl} \\
\left(10^{-15}\right)\end{array}$ & $\begin{array}{c}\mathrm{I} / \mathrm{Cl} \\
\left(10^{-5}\right)\end{array}$ & $\begin{array}{l}\mathrm{Br} / \mathrm{Cl} \\
\left(10^{-5}\right)\end{array}$ \\
\hline & Fumaroles & & & & & & & & & & \\
\hline 1 & Kohachi & KHSI01 & $16 / 4 / 98$ & 874 & 14.36 & 401.35 & 386.49 & $754 \pm 58$ & $0.0 \pm 2.7$ & 3.58 & 96.30 \\
\hline 2 & Kotake Shita & KTKS01 & $11 / 4 / 97$ & 313 & 32.44 & 367.73 & 719.26 & nd & nd & 8.82 & 195.59 \\
\hline 3 & Kotake Shita & KSSI01 & $18 / 4 / 98$ & 420 & 10.83 & 364.23 & 407.74 & $760 \pm 80$ & $0.0 \pm 3.2$ & 2.97 & 111.95 \\
\hline 4 & Oh-Hachi Oku & SV93-2/20 & $27 / 10 / 93$ & 885 & 13.06 & 395.04 & 378.79 & $4360 \pm 190$ & $4.7 \pm 7.8$ & 3.30 & 95.89 \\
\hline 5 & Oh-Hachi Oku & OHOK-01 & $11 / 2 / 97$ & 848 & 13.97 & 418.39 & 415.16 & nd & nd & 3.34 & 99.23 \\
\hline 6 & Kuromoe & SV93-18 & $1 / 11 / 93$ & 720 & 31.19 & 352.83 & 480.61 & $3850 \pm 150$ & $2.8 \pm 4.7$ & 8.84 & 136.22 \\
\hline \multirow[t]{2}{*}{7} & Kotake & KT01 & $11 / 4 / 98$ & 104 & 0.06 & 161.41 & 0.75 & nd & nd & 0.03 & 0.47 \\
\hline & Hot springs & & & & & & & & & & \\
\hline 8 & Heikenojo & SV93-29 & $3 / 11 / 93$ & 63 & 0.54 & 85.98 & 191.79 & $1330 \pm 150$ & $0.0 \pm 10$ & 0.63 & 223.06 \\
\hline 9 & Higashi Onsen & SV93-12 & $28 / 10 / 93$ & 52 & 0.38 & 37.69 & 28.59 & nd & nd & 1.00 & 75.85 \\
\hline \multirow[t]{2}{*}{10} & Yunotake & SV93-31 & $4 / 11 / 93$ & 50 & 0.44 & 62.17 & 90.18 & nd & nd & 0.71 & 145.04 \\
\hline & Seawater & & & & & & & & & & \\
\hline 11 & West Iwodake & SV93-10 & $28 / 10 / 93$ & 24 & 0.32 & 519.61 & 840.69 & nd & nd & 0.062 & 161.74 \\
\hline \multirow[t]{5}{*}{12} & Shin Iwojima & SV93-30 & $4 / 11 / 93$ & 22 & 0.36 & 556.28 & 970.80 & nd & nd & 0.065 & 174.52 \\
\hline & Comparison & Values & & & & & & & & & \\
\hline & Seawater ${ }^{1}$ & & & & 0.44 & 550 & 840 & & & 0.080 & 153 \\
\hline & Pore Fluids & & & & $22^{2}$ & $470^{3}$ & $1060^{3}$ & & & 4.7 & 226 \\
\hline & Meteoric water & & & & $0.045^{4}$ & $0.52^{4}$ & $0.25^{1}$ & & & 8.7 & 48 \\
\hline
\end{tabular}

\footnotetext{
${ }^{1}$ Broecker and Peng (1982).

${ }^{2}$ You et al. (1993).

${ }^{3}$ Kastner et al. (1993).

${ }^{4}$ Takaku et al. (1995).
}

composition of the fluid before it was exposed to surface conditions, i.e. the magmatic component which might have mixed with meteoric water or seawater at or on its way to the surface. The second question relates to the origin of the magmatic component itself, i.e. what sources have contributed to iodine, chlorine, and bromine in the magmatic fluids before they mixed with surface reservoirs.

Concentrations of iodide and bromide in fumaroles (except \#7) are considerably higher than the concentrations in seawater and meteoric water, indicating that the fluids, before mixing with surface waters, had concentrations close to or higher than those found in the fumaroles. The relation between $\mathrm{Cl}$ and I concentrations in samples, on the one hand, seawater and meteoric water on the other, is shown in Fig. 2. Mixing curves were constructed for the magmatic (MAG), meteoric water (MW) and seawater (SW) end-members using the following equations:

$$
\begin{gathered}
M_{\mathrm{MAG}}+M_{\mathrm{MW}}+M_{\mathrm{SW}}=1 \\
C_{\mathrm{obs}}=C_{\mathrm{MAG}} M_{\mathrm{MAG}}+C_{\mathrm{MW}} M_{\mathrm{MW}} \\
+C_{\mathrm{SW}} M_{\mathrm{SW}}
\end{gathered}
$$

where $C$ represents the molar concentration of a given ionic species in solution and $M$ represents the mass fraction of a given end-member. We chose the fumarole with the highest $\mathrm{Cl}$ concentration (\#5) as the magmatic end-member; concentrations for seawater and meteoric water were taken from the literature. The values chosen for the mixing calculations are listed in Table 2. Four of the fumaroles are close together

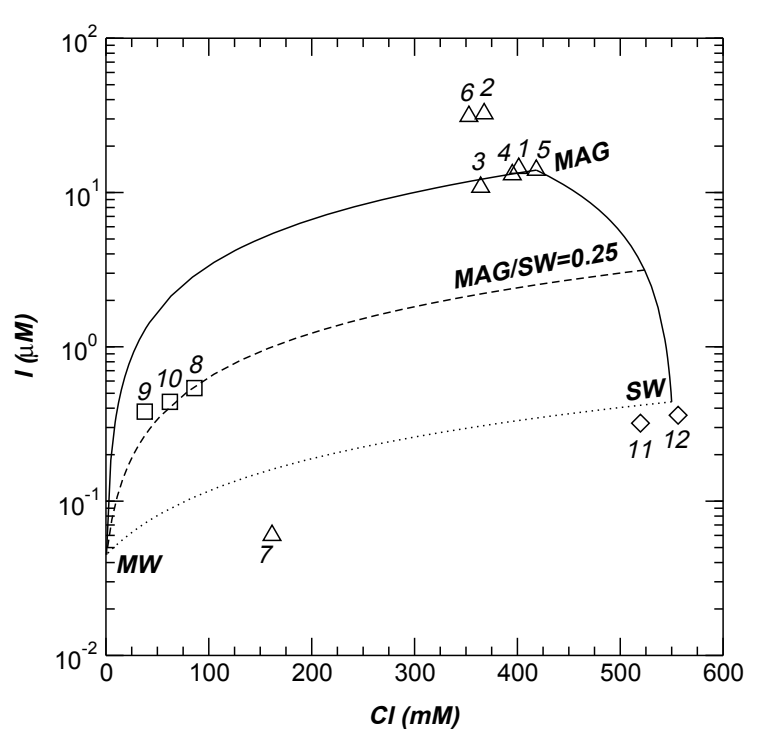

Fig. 2. Iodine vs. chloride concentrations in fumaroles (triangles), seawater (diamonds), and coastal hotsprings (squares). Mixing curves are inidicated between magmatic fluids (MAG), seawater (SW), meteoric water (MW) and a mixture of $25 \% \mathrm{MAG}, 75 \% \mathrm{SW}$ with meteoric water (MW). Sample numbers as in Table 1.

on the plot, indicating a common origin and the presence of small amounts of meteoric water responsible for the shift in concentrations. The two other fumaroles have considerably higher iodine concentrations (together with somewhat elevated $\mathrm{Br}$ concentrations), but have $\mathrm{Cl}$ concentrations sim- 
Table 2. Compostion of potential end-members in the Satsuma-Iwojuma volcanic system.

\begin{tabular}{|c|c|c|c|c|}
\hline End-member & $\begin{array}{c}\mathrm{I} \\
(\mu \mathrm{M})\end{array}$ & $\begin{array}{c}\mathrm{Cl} \\
(\mathrm{mM})\end{array}$ & $\begin{array}{c}\mathrm{Br} \\
(\mu \mathrm{M})\end{array}$ & $\begin{array}{c}{ }^{129} \mathrm{I} / \mathrm{I} \\
\left(10^{-15}\right)\end{array}$ \\
\hline Seawater (SW) & $0.44^{1}$ & $550^{1}$ & $840^{1}$ & $1500^{2}$ \\
\hline Magmatic (MAG) & $14^{3}$ & $418^{3}$ & $415^{3}$ & $780^{4}$ \\
\hline $\begin{array}{l}\text { Pre-anthropogenic } \\
\text { meteoric (PMW) }\end{array}$ & $0.045^{5}$ & $0.52^{5}$ & $0.25^{1}$ & $1500^{2}$ \\
\hline $\begin{array}{l}\text { Anthropogenic } \\
\text { meteoric (AMW) }\end{array}$ & $0.045^{5}$ & $0.52^{5}$ & $0.25^{1}$ & $5000000^{6}$ \\
\hline $\begin{array}{l}{ }^{1} \text { Broecker and Peng ( } \\
{ }^{2} \text { Moran et al. (1998). } \\
{ }^{3} \text { Sample \#5. } \\
{ }^{4} \text { Calculated; see discu } \\
{ }^{5} \text { Avg. from Takaku et } \\
{ }^{6} \text { Estimated from Fehn }\end{array}$ & $\begin{array}{l}\text { 82). } \\
\text { ion in Sul } \\
\text { (1998). } \\
\text { nd Snvde }\end{array}$ & ection 5.2 & & \\
\hline
\end{tabular}

ilar to the other fumaroles. This correlation suggests that concentrations in these two fumaroles reflect enrichment in iodine (and bromine), perhaps related to remobilization of these halogens in the surface environment. The general relation between the samples suggests the absence of seawater in the fumaroles and the presence of only small quantities of meteoric water. Kotake (\#7), a low-temperature fumarole, does not fit the general trend and probably reflects lowtemperature water-rock interactions. In contrast to the fumaroles, hot springs clearly show the presence of meteoric water and probably also of a seawater component. The relation between $\mathrm{Br}$ and $\mathrm{Cl}$ supports the general observations from Fig. 2.

The ${ }^{129}$ I system provides an additional means to determine the identity of mixing end-members (Fig. 3). The mixing equations were modified to differentiate between Preanthropogenic (PMW) and Anthropogenic Meteoric Water (AMW) and to include isotope ratios. PMW has iodine concentrations that are more than two orders of magnitude lower than the magmatic end-member (MAG) and ${ }^{129} \mathrm{I} / \mathrm{I}$ ratios that are roughly twice that of MAG (Table 2). In order to dilute MAG sufficiently to raise the ${ }^{129} \mathrm{I} / \mathrm{I}$ ratios above the precision error (avg. $1-\sigma$ error $=11 \%$ ), PMW:MAG must be at least 32:1. Similarly, seawater (SW) which has a higher concentration than PMW, would have to be added until SW:MAG at least 4:1 for the magmatic ${ }^{129} \mathrm{I} / \mathrm{I}$ ratios to rise above the precision error. The ${ }^{129} \mathrm{I} / \mathrm{I}$ ratio of the magmatic end-member is, however, sensitive to small additions of AMW because the ${ }^{129} \mathrm{I} / \mathrm{I}$ ratio of AMW is more than 3 orders of magnitude higher, even though the iodine concentration is more than 2 orders of magnitude lower in AMW than in MAG. A mixture of AMW:MAG of only 0.006:1 will bring the ${ }^{129} \mathrm{I} / \mathrm{I}$ ratio of the magmatic end-member above the precision error of $11 \%$. Therefore, the magmatic source has ${ }^{129} \mathrm{I} / \mathrm{I}$ ratios which are relatively insensitive to additions of pre-anthropogenic water, and highly sensitive to additions of anthropogenic water. This permits the ${ }^{129}$ I system to distinguish between addition of the two meteoric components. Where an anthropogenic component is present, the age of

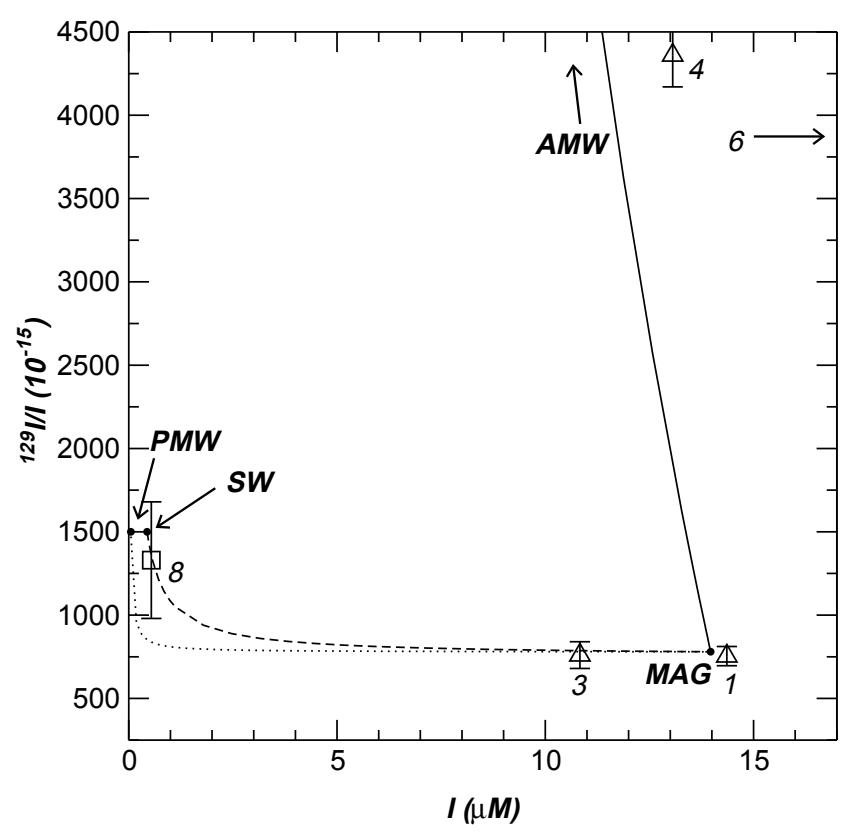

Fig. $3 .{ }^{129} \mathrm{I} / \mathrm{I}$ ratios vs. iodine concentrations showing the mixing curves of magmatic iodine with seawater and meteoric water. In this case, ratios of ${ }^{129} \mathrm{I} / \mathrm{I}$ distinguish between the presence of pre-anthropogenic meteoric water (PMW) and anthropogenic meteoric water (AMW). Symbols as in Fig. 2.

the added groundwater may be assumed to be less than 50 years, since an older age would predate nuclear testing and reprocessing.

Mixing relations in Fig. 2 indicate that the fumaroles contain small amounts of meteoric water, but not seawater. The relationships in Fig. 3 show, that the meteoric water present in \#4 has an anthropogenic component, which is absent in the two fumaroles sampled in $1998(\# 1,3)$. The presence of anthropogenic ${ }^{129} \mathrm{I}$ in Kuromoe (\#6) and in Oh-Hachi Oku (\#4), coupled with the high concentration of I can be explained by the incorporation of iodine, which was deposited during earlier volcanic outgassing at lower temperatures, possibly through adsorption onto metallic sulfides (Fuhrmann et al., 1998). During this period, ${ }^{129}$ I produced by nuclear activities was deposited in rainfall (Fehn and Snyder, 2000) and accumulated near the surface, either through similar adsorption onto sulfides or by direct mineralization (Van Moort, 1985). The resurgence of fumarolic activity in the early 1990s resulted in the remobilization of the adsorbed iodine. The difference in ${ }^{129} \mathrm{I} / \mathrm{I}$ ratios between samples collected in 1993 and 1998 suggests that most surface iodine was removed at the onset of renewed activity and that the results for the 1998 fumaroles reflect the primary composition of the magmatic fluids entering the volcanic system. The only hot spring, which allowed the determination of ${ }^{129} \mathrm{I} / \mathrm{I}$ ratios, Heikenojo (\#8), shows mixing between magmatic and pre-anthropogenic seawater or meteoric water, but does not indicate the presence of anthropogenic meteoric water.

Although the ${ }^{36} \mathrm{Cl} / \mathrm{Cl}$ are all at or below the detection limit of AMS, they can be interpreted in this context. Detectable ${ }^{36} \mathrm{Cl}$ might be present only in the two of the 1993 fumaroles, 
which also have the highest ${ }^{129} \mathrm{I} / \mathrm{I}$ ratios. This observation could suggest that in 1993 the fumaroles contained recent chlorine as well as iodine and that the recent meteoric component was removed during subsequent fumarolic activity. The Heikenojo hot spring also has a low ${ }^{36} \mathrm{Cl} / \mathrm{Cl}$ ratio, although this is probably due to infiltration of sea water, as has been suggested by $\delta^{18} \mathrm{O}, \delta \mathrm{D}$, and tritium results for several coastal springs over the same time period (Goff and McMurtry, 2000).

Because of the large differences in iodine concentration between magmatic fluids and seawater or meteoric water, contributions from magmatic waters dominate the ${ }^{129} \mathrm{I} / \mathrm{I}$ ratios. The ratio is therefore quite independent of the specific mixing proportions and assumptions made in this diagram (Fig. 3). Even if we assume that the initial iodine concentration in the magmatic fluids is that of the fumaroles with the highest concentration observed $(32.5 \mu \mathrm{M}$, \#2), it would lower the presence of the magmatic component in samples \#1 and \#3, but would not shift the ${ }^{129} \mathrm{I} / \mathrm{I}$ ratio in these samples provided that mixing has occurred with preanthropogenic waters (as indicated by the relative shift between \#1 and \#3). The ratios observed for sample \#1 and \#3 are therefore a good representation of the ${ }^{129} \mathrm{I} / \mathrm{I}$ ratios in the magmatic fluids before their exposure to surface fluids.

\subsection{Interpretation of ${ }^{129} \mathrm{I} / \mathrm{I}$ ratios}

The two ratios determined for sample \#1 and \#3 are compared to the decay curve of pre-anthropogenic ${ }^{129} \mathrm{I}$ in Fig. 4. Apparent ages can be calculated using the decay equation:

$$
R_{\mathrm{obs}}=R_{i} e^{-\lambda t}
$$

with the initial marine ${ }^{129} \mathrm{I} / \mathrm{I}$ value of $R_{i}=1500 \times 10^{-15}$ and the decay constant for ${ }^{129} \mathrm{I}, \lambda=4.41 \times 10^{-8} \mathrm{yr}^{-1}$. The two fumaroles yield apparent ages of 15.6 and 15.4

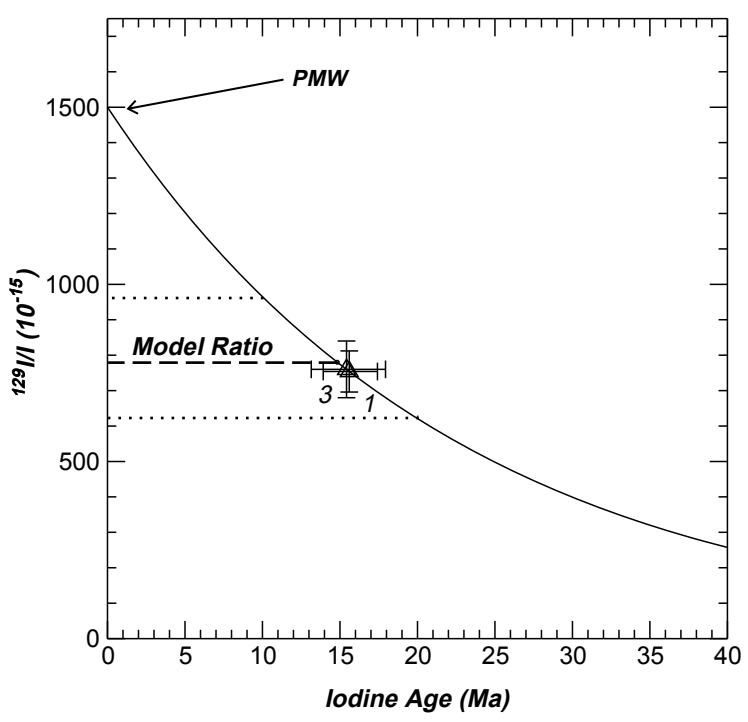

Fig. 4. The ${ }^{129} \mathrm{I} / \mathrm{I}$ ratios of the 1998 high-temperature fumaroles plotted on the decay curve (solid line) for ${ }^{129} \mathrm{I}$, which starts at the pre-anthropogenic marine ratio (PMW). The two ratios fall between the ratios calculated for the youngest and oldest sediments (dotted lines) subducted in the Nankai Trough and are close to the average model ratio (dashed line). Determination of the model ratio as well as the range of ratios for subducted sediments is discussed in Subsection 5.2.
Ma, respectively. Because of the close overlap of results for the two fumaroles, we will use the weighted average $\left(756 \pm 47 \times 10^{-15}\right)$ for the further discussion. Although the hot spring Heikenojo (\#8) has a ratio lower than $R_{i}$ (with an apparent age of $2.7 \mathrm{Ma}$ ) this sample has a substantial presence of pre-anthropogenic surface fluids based on the relations shown in Figs. 2 and 3, and is not used for the further discussion. The apparent ages for the fumaroles are minimum values because contributions from sources other than marine ${ }^{129} \mathrm{I}$ have not been taken into account. Potential additions of ${ }^{129} \mathrm{I}$ could come from in-situ build-up (fissiogenic ${ }^{129} \mathrm{I}$ ), anthropogenic or pre-anthropogenic meteoric or seawater. Significant contributions from the later two sources can be ruled out based on the relations in Figs. 2 and 3. Given the relatively young age of the subduction system in question, contribution of in-situ build-up can also be neglected, so that the ratio and age determined for these two fumaroles can directly be used for the comparison to potential source materials.

To compare the observed ratios to those expected from marine sediments, the tectonic situation under SatsumaIwojima has to be taken into consideration. Iodine could reflect the derivation from one particular layer in the marine sediments or that from the entire subducted sediment column. The marine sediments subducting beneath SatsumaIwojima are between 10 and $20 \mathrm{Ma}$ old, taking into account the age of the sediments under the decollement and the travel time between trench and volcano. These ages result in ratios of $965 \times 10^{-15}$ and $620 \times 10^{-15}$, respectively (dotted lines in Fig. 4), bracketing the observed ratio of $756 \times 10^{-15}$. If iodine is derived from the entire sediment column, a model ratio $R_{\text {mod }}$ can be calculated, assuming uniform distribution of iodine throughout the subducted sediments and using the following equation (Fehn et al., 2001):

$$
R_{\text {mod }}=\frac{R_{i} e^{-\lambda\left(t_{1}+t_{s}\right)}\left(1-e^{-\lambda\left(t_{2}-t_{1}\right)}\right)}{\lambda\left(t_{2}-t_{1}\right)}
$$

where $t_{1}$ and $t_{2}$ are the ages of the youngest and oldest sediments subducted into the trench, and $t_{s}$ is the travel time between trench and volcano. For Satsuma-Iwojima, $t_{1}=5$ $\mathrm{Ma}, t_{2}=15 \mathrm{Ma}$ and $t_{s}=5 \mathrm{Ma}$, which results in an expected average ratio $R_{\bmod }=780 \times 10^{-15}$. Since this ratio is very close to the observed ratio for the two fumaroles $\left(R_{\mathrm{obs}}=756 \times 10^{-15}\right)$ remobilization of iodine from the entire subducted sediments is a good possibility in this case, although, with the few samples available for this study, it is not possible to rule out derivation from one particular sediment level. In either case, an excellent agreement exists between the observed ratios and those expected for the subducted sediments.

Although the most likely derivation of iodine in the fumaroles is from marine sediments, iodine could potentially also be mobilized from the mantle wedge. Relatively little is known about iodine concentrations in the mantle, but McDonough and Sun (1995) give an estimate of $10 \mathrm{ppb}$. Because cosmogenic ${ }^{129} \mathrm{I}$ is absent in the mantle, only ${ }^{129} \mathrm{I}$ produced by the spontaneous fission of ${ }^{238} \mathrm{U}$ is present there. The concentration of ${ }^{129} \mathrm{I}$ in secular equilibrium with ${ }^{238} \mathrm{U}$ is 
given by (Faure, 1986):

$$
N_{129}=\frac{N_{238} Y_{S F} \lambda_{S F}}{\lambda_{129}-\lambda_{S F}}
$$

where $N$ is the number of atoms of ${ }^{129} \mathrm{I}$ and ${ }^{238} \mathrm{U}$, respectively, $Y_{S F}$ is the fission yield for mass $129\left(Y_{S F}=0.0003\right.$; Sabu, 1971) and $\lambda_{S F}$ the decay constant for spontaneous fission of ${ }^{238} \mathrm{U}\left(\lambda_{S F}=8.5 \times 10^{-17} a^{-1}\right)$. With mantle concentrations of $10 \mathrm{ppb}$ for iodine and $20 \mathrm{ppb}$ for uranium (McDonough and Sun, 1995), the expected ratio of ${ }^{129} \mathrm{I} / \mathrm{I}$ in the mantle is $R_{M A}=620 \times 10^{-15}$. Given the uncertainty in mantle values, this ratio is at best an order of magnitude estimate. Although the ratio is close to the results obtained for the fumaroles at Satsuma-Iwojima, two observations make significant iodine input from the mantle highly unlikely: The first problem is that the very low concentration of iodine in the mantle would require channeling of iodine into one volcano from an exceedingly large volume. Secondly, if derivation from the mantle were a major source, ${ }^{129} \mathrm{I} / \mathrm{I}$ should be independent of the age of sediments in subduction zones. In a number of similar investigations of arc volcanoes, ${ }^{129} \mathrm{I} / \mathrm{I}$ ratios were detected, which were different, but compatible with the ages of the sediments subducted in the various arcs (White Island, New Zealand and Copahue, Argentina, studied by Fehn et al., 2001; several volcanoes in Central America, studied by Snyder and Fehn, 2000). Although contributions from the mantle wedge cannot be ruled out, they certainly do not constitute the main source for iodine in these fluids and do not substantially influence the ${ }^{129} \mathrm{I} / \mathrm{I}$ ratios.

\subsection{Origin of the magmatic component}

Halogens are a common constituent of high-temperature fumarolic condensates, almost entirely in the form of hydrogen halides such as $\mathrm{HCl}$ and $\mathrm{HF}$ (Symonds et al., 1988). In general, the halogens tend to have high fluid/melt partition coefficients (Bureau et al., 2000), and extremely high enrichment factors in fumarolic condensates (Symonds et al., 1990; Taran et al., 1995). Their source has been variably interpreted as the result of seawater intrusion (Mazor et al., 1988), subduction recycling (Hedenquist et al., 1994), or contamination from crustal sources (Motyka et al., 1989). The presence of Cl-rich glass inclusions in olivine suggest that at least a portion of the halogens found in arc lavas are derived from a subducted source (Symonds et al., 1990).

The concentrations found in the pore waters of Nankai Trough are very similar to those in the fumarolic condensates, but it is not known whether and to what degree volcanic fluids can be derived directly from the subducted pore waters. Because fluids do not travel unchanged from subduction to recycling, absolute concentrations are not a reliable guide for the origin of fluids, but ratios of the respective halogens in volcanic fumaroles and hot springs may be used to determine potential sources. Although $99 \%$ of the pore fluid in the Nankai is expelled in the fore-arc region (Saffer and Bekins, 1999), the remaining fluid probably has $\mathrm{I} / \mathrm{Cl}$ and $\mathrm{Br} / \mathrm{Cl}$ ratios similar to the initial interstitial waters, because fractionation between the halides is unlikely to occur during dewatering. Preliminary work with the stable ${ }^{37} \mathrm{Cl} /{ }^{35} \mathrm{Cl}$ system in fluids along the Nankai decollement suggests that chloride is incorporated in sediments of the underthrust section (Kastner et al., 2000). Specific data on halide concentrations in sediments of the Nankai Trough are not available, but it is likely that the other halides are incorporated as well, and that the ratios of $\mathrm{I} / \mathrm{Cl}$ and $\mathrm{Br} / \mathrm{Cl}$ in the subducted component are therefore close to those of the pore fluids, which have average ratios of $\mathrm{I} / \mathrm{Cl}=5 \times 10^{-5}$ and $\mathrm{Br} / \mathrm{Cl}=230 \times 10^{-5}$. While this is only an estimate, the similarity to the global average $\mathrm{I} / \mathrm{Cl}$ value for sediments $\left(15 \times 10^{-5}\right.$, Muramatsu and Wedepohl, 1998) makes this a reasonable assumption. The observation that the halogen ratios in the bulk composition of the Satsuma-Iwojima igneous rocks (which presumably contain the halides in both the rock matrix and fluid inclusions) are close to those of the pore fluids strengthens this argument. While the observed ratios in the fumaroles are close to those found in marine sediments, they are very different from that in seawater. The $\mathrm{I} / \mathrm{Cl}$ ratio for seawater is only $0.08 \times 10^{-5}$, due to biotic scavenging (Broecker and Peng, 1982). The transfer of iodine to the atmosphere as methyl iodide greatly increases $\mathrm{I} / \mathrm{Cl}$ ratios in rain and river water relative to the ocean. The average $\mathrm{I} / \mathrm{Cl}$ ratio for rivers in Japan is $8.7 \times 10^{-5}$ (Takaku et $a l ., 1995)$. This ratio is close to the observed ratio in the volcanic fluids; but, given the tectonic setting, input of meteoric fluids is much less likely than derivation of the magmatic end-member from marine sediments. Similar enrichments and depletions occur, although to a lesser degree, with $\mathrm{Br} / \mathrm{Cl}$ ratios (Table 1 ).

Once subducted and incorporated into magmatic systems, the relative abundance of iodine, chlorine, and bromine will be subject to partitioning between fluid and melt phases. Experimental data in albitic melts suggests that the $\mathrm{D}_{f / m}$ values are 8.1 for $\mathrm{Cl}, 17.5$ for $\mathrm{Br}$, and 104 for I (Bureau et al., 2000). Provided that the volume of fluid is small relative to the melt, and assuming a starting composition similar to the Nankai pore fluids, the magmatic I/Cl ratio is $60 \times 10^{-5}$, and $\mathrm{Br} / \mathrm{Cl} 487 \times 10^{-5}$. If the fluid $/ \mathrm{melt}$ ratio is high, however, the halide ratios should be similar to the starting composition. The ratios for pore fluids (perhaps reflecting those of marine sediments in the Nankai Trough) are closest to the observed ratios for the two samples with the least amount of surface components present. This observation, as well as the interpretation of the ${ }^{129} \mathrm{I}$ results, indicates that marine sediments are the dominant source of halides in the magmatic fluids and that ratios remain quite unaffected during transport from the subduction zone to the volcanic fluids. The similarity of halogen ratios between sediment fluids and fumaroles suggests that all three halogens are recycled at similar rates from the sediments into volcanic fluids and, given the substantial differences in distribution coefficients between the halogens, that this reflects a high fluid/melt ratio in this system. Contributions from the mantle wedge to the halogen budget of the volcanic fluids cannot be ruled out based on this comparison, but are likely to be small.

This study is one of the first attempts to use the ${ }^{129}$ I system for the tracing of marine sediments in subduction zones. The only direct comparison possible to data from another geologic setting are preliminary observations from the White Island volcano, New Zealand, associated with the subduction of the Pacific Plate beneath the Indo-Australian Plate. Fumaroles at White Island, New Zealand, have $\mathrm{I} / \mathrm{Cl}$ ratios 
of $5.5 \times 10^{-5}$, and $\mathrm{Br} / \mathrm{Cl}$ ratios of $470 \times 10^{-5}$ (Tedesco and Toutain, 1991), reasonably close to the ratios observed in Satsuma-Iwojima. The ${ }^{129} \mathrm{I} / \mathrm{I}$ ratios found there are close to $300 \times 10^{-15}$, considerably lower than those in SatsumaIwojima, but are compatible with derivation from sediments with ages typical for the specific subduction zone, which range there between 0 and $80 \mathrm{Ma}$ (Fehn et al., 2001).

\subsection{Estimates of iodine fluxes}

The flux of chloride in the form of gases and aerosols from the Satsuma-Iwojima volcano is $6 \times 10^{4} \mathrm{t} / \mathrm{yr}$, based on the high-temperature fumarole composition and $\mathrm{SO}_{2}$ flux determinations through correlation spectrometry. The flux of chloride from the acidic hot springs is estimated at $3.6 \times$ $10^{4} \mathrm{t} / \mathrm{yr}$ (Hedenquist et al., 1994). Assuming an average atomic $\mathrm{I} / \mathrm{Cl}$ ratio for the hot fumaroles $\left(5.1 \times 10^{-5}\right.$, excluding cold fumarole \#7), and an average $\mathrm{I} / \mathrm{Cl}$ ratio of $0.78 \times 10^{-5}$ for the hot springs, the total flux of iodine from the volcano is $12 \mathrm{t} / \mathrm{yr}$, of which $11 \mathrm{t} / \mathrm{yr}$ comes directly from the fumaroles. This is comparable to the flux of iodine from White Island, New Zealand, which is $7 \mathrm{t} / \mathrm{yr}$ (Tedesco and Toutain, 1991). Using a similar approach with global volcanic emissions of chloride (Symonds et al., 1988) and assuming that the Satsuma-Iwojima $\mathrm{I} / \mathrm{Cl}$ ratios are representative for the global flux, the global iodine flux can be estimated to be between 70 and $2000 \mathrm{t} / \mathrm{yr}$.

\section{Conclusion}

Based on the comparison of halogen concentrations and ${ }^{129} \mathrm{I} / \mathrm{I}$ ratios in hot springs and fumarolic condensates of Satsuma-Iwojima, a magmatic component common to these fluids was identified. The other end-members are meteoric water, with or without the presence of anthropogenic ${ }^{129} \mathrm{I}$, and seawater, which are present at various degrees in fumaroles and hot springs. The magmatic end-member is best preserved in two fumaroles sampled in 1998 and has a ${ }^{129} \mathrm{I} / \mathrm{I}$ ratio of $756 \pm 47 \times 10^{-15}$, corresponding to an age of $15.5 \pm$ 1.5 Ma. Ratio and age can be compared to those expected for the marine sediments subducted in the Nankai Trough, which, with ages between 10 and $20 \mathrm{Ma}$, bracket the age calculated for the magmatic end-member. If iodine is derived from the entire subducted sediment column, an average ratio of $780 \times 10^{-15}$ is calculated, which is very close to the observed ratio. The excellent agreement between the observed ratio and the ratios predicted for the marine sediments strongly suggests derivation of iodine in the volcanic fluids from marine sediments, most likely as a mobilization from the entire subducted sediment column, although derivation from a specific layer (with an age of $15.5 \pm 1.5$ Ma) cannot be ruled out based on the few data points available. Derivation of iodine and the other halogens from marine sediments is also supported by a comparison of $\mathrm{I} / \mathrm{Cl}$ and $\mathrm{Br} / \mathrm{Cl}$ ratios of the magmatic end-member to those in pore fluids observed in the sediments of the Nankai Trough (ODP 808).

In addition to determining the brine source, the ${ }^{129}$ I system permits assessment of the evolution of meteoric input over time. Fumaroles collected in 1993 contained iodine from surface water less than 50 years old, as well as measurable tritium. The period of increased activity and reorganization of fumaroles between 1993 and 1998 probably removed any recent iodine that might have accumulated in the system. The ${ }^{36} \mathrm{Cl}$ system also confirms that the input of recent meteoric water is negligible in all but the $1993 \mathrm{fu}-$ maroles.

The most important finding of this study is the good correlation between the observed iodine ages for two fumaroles and the age of the subducting sediments in this region. This observation strongly suggests the remobilization of iodine and, by association, of other volatiles from subducting sediments in this region. The results suggest that halides that at one time resided in the marine sediments are presently emerging in an arc volcano, and that the ${ }^{129}$ I system can provide a time signature for the source of magmatic volatiles.

Acknowledgments. We appreciate discussions with Jeff Hedenquist who first stimulated our interest in the ${ }^{129} \mathrm{I}$ analysis of Japanese fumaroles. Our sincere thanks goes to Hiroshi Shinohara of the Geological Survey of Japan who organized the project on Satsuma-Iwojima and provided us with the samples collected in 1997 and 1998. We also wish to thank Pankaj Sharma and David Elmore of PRIME Laboratory, Purdue University, for carrying out the analysis of ${ }^{36} \mathrm{Cl}$ and ${ }^{129} \mathrm{I}$, and $\mathrm{H}$. Shinohara, Y. Muramatsu, and M. Pennisi for helpful comments on the paper. Iodine and bromine concentrations were determined at the ICP-MS Laboratory of the University of Rochester. The research was supported in part by NSF grant EAR-9902919 to UF.

\section{References}

Broecker, W. S. and T. H. Peng, Tracers in the Sea, Eldigio Press, Columbia Univ., 690 pp., 1982.

Bureau, H., H. Keppler, and N. Métrich, Volcanic degassing of bromine and iodine: experimental fluid/melt partitioning data and applications to stratospheric chemistry, Earth Planet. Sci. Lett., 183, 51-60, 2000.

Fabryka-Martin, J., H. Bentley, D. Elmore, and P. L. Airey, Natural Iodine129 as an Environmental Tracer, Geochim. Cosmochim. Acta, 49, 337347, 1985.

Faure, G., Principles of Isotope Geology, John Wiley and Sons, New York, 589 pp., 1986.

Fehn, U. and G. Snyder, ${ }^{129}$ I in the Southern Hemisphere: global redistribution of an anthropogenic isotope, Nucl. Inst. Meth. Phys. Res. B, 172, 366-371, 2000.

Fehn, U., E. K. Peters, S. Tullai-Fitzpatrick, P. W. Kubik, P. Sharma, R. T. D. Teng, H. E. Gove, and D. Elmore, ${ }^{129} \mathrm{I}$ and ${ }^{36} \mathrm{Cl}$ concentrations in waters of the eastern Clear Lake area, California: Residence times and source ages of hydrothermal fluids, Geochim. Cosmochim. Acta, 56, 2069-2079, 1992.

Fehn, U., G. T. Snyder, and P. K. Egeberg, Dating of pore fluids with ${ }^{129} \mathrm{I}$ : Relevance for the Origin of Marine Gas Hydrates, Science, 289, 23322335, 2000

Fehn, U., G. T. Snyder, and J. Varekamp, Detection of recycled marine sediment components in crater lake fluids using ${ }^{129} \mathrm{I}, \mathrm{J}$. Volcanol. Geotherm. Res., 2001 (in press).

Fuhrmann, M., S. Bajt, and M. A. A. Schoonen, Sorption of iodine on minerals investigated by $\mathrm{X}$ ray absorption near edge structure (XANES) and ${ }^{125}$ I tracer sorption experiments, App. Geochem., 13, 127-141, 1998.

Gélinas, Y., A. Krushevska, and R. M. Barnes, Determination of Total Iodine in Nutritional and Biological Samples by ICP-MS Following their Combustion within an Oxygen Stream, Anal. Chem., 70, 1021-1025, 1998.

Goff, F. and G. M. McMurtry, Tritium and stable isotopes of magmatic waters, J. Volcanol. Geotherm. Res., 97, 347-396, 2000.

Hedenquist, J. W., F. Goff, F. M. Phillips, D. Elmore, and M. K. Stewart, Groundwater Dilution and Residence Times, and Constraints on Chloride Source in the Mokai Geothermal System, New Zealand, from Chemical, Stable Isotope, Tritium, and ${ }^{36} \mathrm{Cl}$ Data, J. Geophys. Res., 95, 1936519375, 1990.

Hedenquist, J. W., M. Aoki, and H. Shinohara, Flux of volatiles and oreforming metals from the magmatic-hydrothermal system of Satsuma Iwojima volcano, Geology, 22, 585-588, 1994.

Kanzaki, T., M. Yoshida, M. Nomura, H. Kakihana, and T. Ozawa, Boron isotopic composition of fumarolic condensates and sassolites from Sat- 
suma Iwo-Jima, Japan, Geochim. Cosmochim. Acta, 43, 1859-1863, 1979.

Kastner, M., H. Elderfield, W. J. Jenkins, J. M. Gieskes, and T. Gamo, Geochemical and isotopic evidence for fluid flow in the Western Nankai subduction zone, Japan, in Hill, I. A., A. Tiara, J. V. Firth et al., Proc. ODP, Sci. Results, 131, 397-407, 1993.

Kastner, M., A. Spivack, and L. Becker, Fluid Composition, Origin, and Flow in the Nankai Trough Subduction Zone (abstract), EOS Trans., V21, G08, 2000.

Matsuo, S., T. Suzuoki, M. Kusakabe, H. Wada, and M. Suzuki, Isotopic and chemical compositions of volcanic gases from Satsuma-Iwojima, Japan, Geochem. J., 8, 165-173, 1974.

Mazor, E., R. Cioni, E. Corassa, M. Fratta, G. Magro, S. Matsuo, H. Hirabayashi, H. Shinohara, M. Martini, G. Piccardi, and P. CelliniLegittimo, Evolution of fumarolic gases-boundary conditions set by measured parameters: case study at Vulcano, Italy, Bul. Volcanol., 50, 71-85, 1988.

McDonough, W. F. and S.-S. Sun, The composition of the Earth, Chem. Geol., 120, 223-253, 1995.

Moran, J. E., U. Fehn, and J. S. Hanor, Determination of source ages and migration of brines from the U.S. Gulf Coast basin using ${ }^{129} \mathrm{I}$, Geochim. Cosmochim. Acta, 24, 5055-5069, 1995.

Moran, J. E., U. Fehn, and R. T. D. Teng, Variations in ${ }^{129} \mathrm{I} /{ }^{127} \mathrm{I}$ ratios in recent marine sediments: evidence for a fossil organic component, Chem. Geol., 152, 193-203, 1998.

Motyka, R. J., R. J. Poreda, and A. W. A. Jeffrey, Geochemistry, isotopic composition, and origin of fluids emanating from mud volcanoes in the Copper River basin, Alaska, Geochim. Cosmochim. Acta, 53, 29-41, 1989.

Muramatsu, Y. and K. H. Wedepohl, The distribution of iodine in the earth's crust, Chem. Geol., 147, 201-216, 1998.

Olafsson, G., Calcareous nannofossil biostratigraphy of the Nankai Trough, in Hill., I. A., A. Tiara, J. V. Firth et al., Proc. ODP, Sci. Results, 131, 3-13, 1993.

Rao, U., U. Fehn, R. T. D. Teng, and F. Goff, Sources of chloride in hydrothermal fluids from the Valles caldera, New Mexico: a ${ }^{36} \mathrm{Cl}$ study, $J$. Volcanol. Geotherm. Res., 72, 59-70, 1996.

Sabu, D. D., On mass-yield of xenon and krypton isotopes in the spontaneous fission of uranium, J. Inorg. Nucl. Chem., 33, 1509-1513, 1971.

Saffer, D. M. and B. Bekins, Fluid budgets at convergent plate margins: Implications for the extent and duration of fault-zone dilation, Geology, 27, 1095-1098, 1999.

Schnetger, B. and Y. Muramatsu, Determination of the halogens, with special reference to iodine, in geological and biological samples using pyrohydrolysis for preparation and inductively coupled plasma mass spectrometry and ion chromatography for measurement, Analyst, 121, 16271631, 1996.

Sharma, P., M. Bourgeois, D. Elmore, D. Granger, M. E. Lipschutz, X. Ma, T. Miller, K. Mueller, G. Rickey, P. Simms, and S. Vogt, PRIME Lab
AMS performance, upgrades and research applications, Nucl. Inst. Met. Phys. Res. B, 172, 112-123, 2000.

Shinohara, H., W. F. Giggenbach, K. Kazahaya, and J. W. Hedenquist, Geochemistry of volcanic gases and hot springs of Satsuma-Iwojima, Japan: Following Matsuo, Geochem. J., 27, 271-285, 1993.

Shinohara, H., K. Kazahaya, G. Saito, N. Matsushima, and Y. Kawanabe, Degassing activity from Iwodake rhyolitic cone, Satsuma-Iwojima volcano, Japan: Formation of a new degassing vent, 1990-1999, Earth Planet Space, 54, this issue, 175-185, 2002.

Snyder, G. and U. Fehn, ${ }^{129}$ I in volcanic fluids: testing for the presence of marine sediments in the Central American volcanic arc, Nucl. Inst. Met. Phys. Res. B, 172, 568-573, 2000.

Snyder, G. T., W. C. Riese, S. G. Franks, J. E. Moran, and U. Fehn, Paleohydrology of a coal-bed methane reservoir: I-129 and Cl-36 results for the Fruitland Formation, CO., Geol. Soc. Am. Abstr., 32, 359, 2000.

Symonds, R. B., W. I. Rose, and M. H. Reed, Contribution of Cl- and Fbearing gases to the atmosphere by volcanoes, Nature, 334, 415-418, 1988.

Symonds, R. B., W. I. Rose, T. M. Gerlach, P. H. Briggs, and R. S. Harmon, Evaluation of gases, condensates, and $\mathrm{SO}_{2}$ emissions from Augustine volcano, Alaska: the degassing of a Cl-rich volcanic system, Bull. Volcanol., 52, 355-374, 1990.

Takaku, Y., T. Shimamura, K. Masuda, and Y. Igarashi, Iodine determination in Natural and Tap Water Using Inductively Coupled Plasma Mass Spectrometry, Anal. Sci., 11, 823-827, 1995.

Taran, Y. M., J. A. Hedenquist, M. A. Korzhinsky, S. I. Tkachenko, and K. I. Schmulovich, Geochemistry of magmatic gases from Kudryavy Volcano, Iturup, Kuril Islands, Geochim. Cosmochim. Acta, 59, 1749-1761, 1995.

Tedesco, D. and J. P. Toutain, Chemistry and Emission Rate of Volatiles from White Island Volcano (New Zealand), Geophys. Res. Lett., 18, $113-$ $116,1991$.

Urrutia, J. and O. Morton, Long-term evolution of subduction zones and the development of wide magmatic arcs, Geofisica Int., 2, 24, 1997.

Van Moort, J. C., Procesos naturales de enriquecimiento de nitratos, sulfatos, cloruros, iodatos, boratos, percloratos y cromatos en los caliches del norte de Chile, Actas-Congreso Geológico Chileno, Universidad del Norte, 3, 674-702, 1985.

Yoshida, M., K. Takahashi, N. Yonehara, T. Ozawa, and I. Iwasaki, The Fluorine, Chlorine, Bromine, and Iodine Contents of Volcanic Rocks in Japan, Bul. Chem. Soc. Japan, 44, 1844-1850, 1971.

You, C.-F., J. M. Gieskes, R. F. Chen, A. Spivack, and T. Gamo, Iodide, bromide, manganese, boron, and dissolved organic carbon in interstitial waters of organic carbon-rich marine sediments: observations in the Nankai accretionary prism, in Hill, I. A., A. Tiara, J. V. Firth et al., Proc. ODP, Sci. Results, 131, 165-173, 1993.

G. T. Snyder (e-mail: glen@earth.rochester.edu), U. Fehn, and F. Goff 